\title{
TEACHING STYLES
}

\section{The challenge of providing mentorship in primary care}

\section{Sheona MacLeod}

Postgrad Med J 2007;83:317-319. doi: 10.1136/pgmj.2006.054155

In the changing National Health Service, there is an increasing awareness of stress related problems in the medical workforce. Mentorship has been shown to help with both stress reduction and adaptation to change. There are recognised difficulties with providing mentorship for doctors but there are ways in which these can be overcome. The medical profession is now considering revalidation, re-certification, and the standards required for these. Perhaps it is also time to consider ways in which mentorship can be provided to support the medical workforce, promote ongoing development and thus improve our ability to care for patients.

Correspondence to: Dr Sheona MacLeod, Trent Deanery, Ashbourne Health Centre, Compton, Ashbourne, Derby, DE6 1DA, UK; sheonamacleod@ aol.com

Received 2 October 2006 Accepted 2 October 2006
A s the National Health Service (NHS) continues to try to adapt to changing pressures, there is increasing awareness of stress related problems in the medical workforce. ${ }^{1}$ Mentorship has been shown to help with both stress reduction ${ }^{2}$ and adaptation to change. ${ }^{3}$ The medical profession is now considering revalidation, re-certification, and standards to promote good medical practice. It is perhaps time to increase the provision of mentorship schemes and thus promote the development of all doctors working in the changing NHS.

\section{HISTORY}

"Mentorship" has perhaps always existed. There are numerous examples throughout history, including the relationship between Telemarchus and the man entrusted with his development, Mentor, who gave his name to the concept. However, the interpretation of Mentor's role has varied and the description of the role varies in literature from different professions and cultures.

Formal mentoring schemes for general practitioners have been established since the early 1990s. Some were primarily for general practitioners $^{4}$ and others expanded to include them. ${ }^{5}$ However, the provision of mentoring remains variable and it is not yet available for all, despite this recommendation by the Standing Committee on Postgraduate Medical and Dental Education (SCOPME) report in $1998 .{ }^{6}$

The essence of mentoring has been defined as a learning relationship ${ }^{5}$ to help people help themselves. $^{7}$ This promotion of learning was the primary driver for many mentoring schemes. Yet in practice, the schemes expanded their educational focus to include other issues, ${ }^{4}$ finding benefits in stress reduction ${ }^{2}$ and support for doctors at times of change. ${ }^{3}$ Mentoring has also been seen as a way of helping recruitment and retention, ${ }^{58}$ and underperformance. ${ }^{9}$

\section{DEFINITION}

Although mentoring is recognised as being beneficial, ${ }^{9}{ }^{10}$ many authors acknowledge the difficulty in defining mentoring. ${ }^{11}{ }^{12}$ For doctors the SCOPME description of the process is often quoted. ${ }^{6}$

\begin{abstract}
"The process whereby an experienced, highly regarded, empathic person (the mentor), guides another individual (the mentee) in the development and re-examination of their own ideas, learning, and personal and professional development. The mentor, who often, but not necessarily, works in the same organisation or field as the mentee, achieves this by listening and talking in confidence to the mentee" SCOPME $1998^{\circ}$
\end{abstract}

A mentor's role varies with the needs of the organisation $^{13}$ and an effective mentor may embody a spectrum of roles. ${ }^{3}$ As mentoring relationships are developmental, ${ }^{5}$ this role may change as the relationship develops.

\section{BENEFITS OF MENTORSHIP}

It has been difficult to quantify the value of mentoring schemes but there is evidence of benefits to the individual, and to the wider network of their family and colleagues, and to patients and the NHS. ${ }^{3}$ Mentorship allows individuals to maximise their potential. ${ }^{10}$ But it is not just the mentee who benefits as the mentoring relationship is also described as being beneficial to the mentor.

As a knowledge based industry, the NHS could benefit from the promotion of learning, broadened perspectives and improved communication that result from mentoring; ${ }^{3}$; and as mentorship improves work performance, ${ }^{9}$ personal development and needs based learning, ${ }^{15}$ it should improve standards of care for patients.

\section{CHALLENGES}

Despite the documented benefits, Freeman ${ }^{13}$ warns that mentoring faces the danger of being perceived as a panacea for all ills. It is not without problems.

Mentoring is an interaction between individuals, and this relationship can become dysfunctional. Long described this when considering the "dark side" of mentoring in $1994 .^{16}$

In establishing this relationship, the lack of clarity as to what exactly mentoring is does not

Abbreviations: NHS, National Health Service; SCOPME, Standing Committee on Postgraduate Medical and Dental Education 
help the mentee and mentor. Problems can arise because of lack of understanding of the roles ${ }^{16}$ or the boundaries in the relationship. ${ }^{17}$ The caring nature of the profession means informal support is often offered to fellow professionals. ${ }^{12}$ Although beneficial, this may not acknowledge the commitment of the mentor, and as pressure of time makes it difficult for doctors to commit to a mentoring relationship, the few available mentors can risk overload. There is also a risk that mentoring inappropriately becomes personal therapy.

Mentoring uses many of the skills needed in medicine, but doctors do not necessarily make good mentors. ${ }^{18}$ Medical training encourages doctors to solve problems with a diagnosis and a cure, rather than guiding people to their own way of sorting them. ${ }^{13}$ Mentors should help people address problems, not sort problems for them. Mentors can become stressed by taking the mentees' problems onboard. ${ }^{2}$

Mentorship should recognise the relationship between personal and professional life. ${ }^{13}$ So exploration and challenge of these personal values may be needed to help people move forward. Yet mentors may find it difficult to address such problems. $^{5}$

It is also difficult to create the balance between support and challenge. There is a risk of producing dependency by providing too much support ${ }^{16}$ and thus developing a "halo"17 such that the mentee does not question the mentor's opinions. Mentees can be more sensitive to criticism and their self-confidence can be undermined with negative feedback, ${ }^{13}$ yet challenge may be needed to help people move forward.

Similar personality types find it easier to communicate and establish a rapport, and differences in personality between mentor and mentee can lead to problems. ${ }^{18}$ However, having a mentor of a similar personality may allow the mentee to remain within their "comfort zone" and more learning might be gained from someone who looks at the world from a different perspective. ${ }^{19}$

The mentoring relationship can be difficult when a mentor is senior in position, especially if they are involved in their assessment or future career prospects. Juniors can then be inhibited from openly discussing problems. ${ }^{8}$ However, when there is a different mentor and supervisor, problems can arise from the senior doctor feeling threatened or excluded by a mentoring relationship. Other colleagues may also be jealous of the mentoring relationship. ${ }^{17}$

Gender differences can cause problems, with over-protection encouraging dependency, ${ }^{16}$ sexual attraction, and problems from others perceptions of the mentoring relationship.

An awareness of the possibility of some problems may be enough to promote recognition and discussion to address them.

Making a mentorship 'contract' is frequently advocated..$^{13}{ }^{17}$ This allows definition of the relationship's boundaries, reduces confusion about roles and expectations, clarifies commitments including time, and defines the relationship's objectives. However, making formal contracts may stifle informal support. ${ }^{20}$ As a minimum, it seems sensible to clarify both participants' expectations of a relationship.

Training for mentors has been recognised as important for successful mentoring. ${ }^{821}$ Freeman $^{13}$ developed a model to help mentors address both personal and professional issues, and training like this promotes mentors' self-confidence in tackling problems.

The provision of a support group helps mentors share learning and decreases stress. ${ }^{25}$ They also help the mentor stick to agreed roles and boundaries, ${ }^{13}$ yet many areas lack any formal mentorship support scheme to provide this.

Providing mentorship as part of a scheme also provides people with a choice of possible mentors. The provision of information about these schemes could perhaps increase understanding of the potential benefits and could decrease the stigma attached.

\section{COULD YOU BE A MENTOR?}

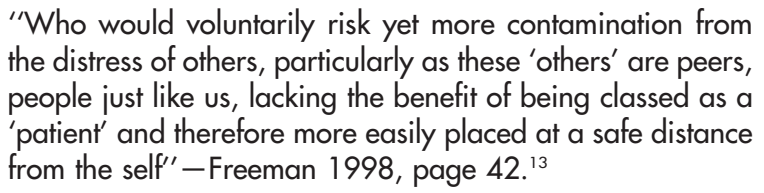

The attributes of a good mentor can be derived from considering the activities involved in good mentorship practice.

As a safe trusting environment is needed, a mentor needs to be supportive, compassionate, sensitive to the needs of others, and respectful of their views. ${ }^{23}$ This requires a degree of humility and an appreciation of diversity.

A non-judgmental impartial approach is recommended with empathetic listening skills, ${ }^{2}$ and both verbal and non-verbal communication skills are important. ${ }^{172}$ As feedback is an important part of mentoring, the mentor needs to be tactful and able to both provide positive and negative feedback, and to receive it. ${ }^{17}$ The experience of being a mentee also helps develop mentoring skills. ${ }^{22}$

Mentors need self-awareness and a commitment to selfdevelopment and learning from their peers. ${ }^{13}$ They are seen as being wise and experienced, ${ }^{6}$ with the benefit of the experience of both failure and success. ${ }^{2}$ They need the motivational skills $^{318}$ and the enthusiasm to help develop others.

As mentorship also involves challenge, mentors need the selfconfidence and security in their own positions to be able to confront difficulties and employ negotiating skills to resolve them. ${ }^{18}$

A mentor who is flexible in their thinking is more likely to be able to help others find alternative approaches. ${ }^{22}$

As well as having the right attributes the mentor needs to be prepared to give time and energy to the task. ${ }^{6}$

There are few people with all these attributes, but the skills can be developed. ${ }^{13}$ Mentorship itself is a developmental activity for both the mentor and mentee.

The attributes of the mentee also affect the process. Having an acceptance of challenge, a commitment to the mentoring process and a recognition of realistic boundaries and possible outcomes, increase the benefits of the relationship. ${ }^{3}$ Some businesses with mentoring schemes provide information for mentees, to help employees get the most from them. It has been suggested that there should be a mechanism for preparing doctors to maximise the benefits of being a mentee. ${ }^{7}$

\section{FUTURE CHALLENGES}

Stress is increasingly recognised in the medical profession, ${ }^{123}$ and providing adequate systems of support is not only in the doctors' interest but also in the interest of their patients. ${ }^{24}$ Mentorship could be of value to many doctors, but there needs to be a change in how it is generally perceived before some doctors will consider its use. ${ }^{7}$ If mentorship is only arranged when there are performance problems it will be met with resistance. ${ }^{24}$ Awareness of the potential benefits needs to be raised within the profession ${ }^{9}$ so that doctors know what they could gain from a mentoring relationship.

Roberts ${ }^{24}$ suggests there should be provision of mentorship for doctors along with formal evaluation irrespective of performance. This may become increasingly necessary as doctors go through any new re-certification or revalidation procedures. However, any formal provision should not prevent continuation of the informal support that exists at present within the medical profession. ${ }^{20}$ 
Multi-professional team working is increasing. Mentorship has been shown to promote the working of a multiprofessional team, with doctors benefiting from mentorship both from outside the profession ${ }^{25}$ and from outside medicine. ${ }^{26}$ Mentoring is traditionally seen as a single relationship, but it may be more appropriate to have different mentors for different roles. ${ }^{7}$ Mentoring teams have been suggested for nurses as a solution to the problem of any one mentor being unable to possess all the necessary attributes. ${ }^{27}$ Joesbury et $a^{28}$ found different people could contribute to an under-performing doctor's development. A multi-professional mentoring team could be an appropriate model for mentoring in the future.

The pressure on time will continue, but new initiatives in mentorship can help this. Email mentoring could increase ${ }^{20}$ and mentoring on the phone has been considered ${ }^{29}$ These communication methods could be used as extensions of an existing relationship but could also develop to provide ways of increasing the provision of mentorship on their own.

The British Medical Association suggest that feedback from mentoring schemes should lead to improvements and that monitoring and evaluation can increase mentoring scheme effectiveness. Evaluation of mentorship usually concentrates on participant satisfaction, but information about behaviour changes in the workplace and wider benefits to the NHS are also needed. These improvements are more difficult to link purely to the mentoring process. However, they are more likely to prove the worth of a scheme to those who can finance its continuation. Investment in mentor training and support is needed to increase the effectiveness of the relationship. ${ }^{80}$ However, with the present pressure on finance in the NHS, possible benefits to patients and the organisation may need to be more carefully evaluated.

It is recognised that there are times when the need for mentorship is greater than others. However, as the NHS changes and doctors face increasing change throughout their career, it is perhaps more important to make mentors available to all doctors, whatever their age and stage of their professional life. Mentoring is not without costs but with the benefits to the individuals and the NHS, it is worthy of the investment.

Conflict of interest: none stated

\section{REFERENCES}

1 Symons L, Persaud R. Stress among doctors BMJ 1995;310:742.

2 Alliot R. (1996) Facilitatory mentoring in general practice. BMJ Career focus 313 :2 http://bmi.bmijournals.com/cgi/content/full/313/7076/S2-7076 (accessed 4 Jan 2006), (7060).

3 Dancer JM. Mentoring in healthcare: theory in search of practice? Clinician in Management 2003:12:21-31.

4 Sloan R, Taylor G. The impact of general practitioners trained as mentors: a study of mentoring activity and potential. Mentoring and Tutoring 2003;11:321-30.

5 Connor MP, Bynoe AG, Redfern N, et al. Developing senior doctors as mentors: a form of continuing professional development. Report of an initiative to develop a network of senior doctors as mentors: 1994-99, Medical Education 2000;34:747-53.

6 Standing Committee on Postgraduate Medical and Dental Education. An enquiry into mentoring supporting doctors and dentists at work, SCOPME, 1998.

7 Oxley J, Flemming B, Golding L, et al. Improving working lives for doctors. Mentoring for doctors: enhancing the benefit, A working paper produced on behalf of the Doctors' Forum. London: Department of Health London, 2003.

8 Bregazzi R, Harrison J, Van Zwanenberg. Mentoring new GPs: experience from GP career start in County Durham. Education for General Practice 2000;1 1:58-64.

9 British Medical Association. Board of Medical Education exploring mentoring policy report. London: BMA Publishing, 2004.

10 Pietroni R, Palmer A. Portfolio based learning and the role of mentors. Education for General Practice 1995;6:111-14.

11 Oliver C, Aggleton A. Mentoring for professional development in health promotion: a review of issues raised by recent research. Health Education 2002;102:30-8.

12 Bligh J. Mentoring: an invisible support network. Medical Education 1999:33:2-3.

13 Freeman R. Mentoring in general practice. Oxford: Butterworth Heinnemann, 1998.

14 Challis M, Mathers NJ, Howe AC, et al. Porffolio-based learning: continuing medical education for general practitioners- a mid-point evaluation. Medica Education 1997:31:22-6.

15 Hibble A, Berrington R. Personal professional learning plans-an evaluation of mentoring and co-tutoring in general practice. Education for General Practice 1998;9:216-21.

16 Long J. The dark side of mentoring. AARE Conference Newcastle, 1994. http:// www.aare.edu.au/94pap/longi94030.txt (accessed 10 January 2006).

17 Bayley H, Chambers R, Donoval C. The good mentoring toolkit for healthcare. Oxford: Radcliffe Publishing, 2004.

18 Cohen C, Rooney G, Maw R, et al. Mentoring. Clinical Medicine 2004;4:584-6.

19 Chambers R. Find yourself a mentor. BMJ Careers Focus 2005:330:170.

20 Oxley J, interviewed in MacDonald R. Mentoring for doctors. BMJ Career Focus 2004;328:179.

21 Snell J. Head to head. Health Service Journal 1999;109:22-5.

22 lingham S, Gupta R. Mentoring for overseas doctors. BMJ 1998;317:S2.

23 Taylor F. Will you burn out? BMJ Career Focus 2005;331:220.

24 Roberts G, Moore B, Coles C. Mentoring for newly appointed consultant psychiatrists. Psychiatric Bulletin 2002;26:106-9.

25 Bellman L. Evaluation of a multiprofessional mentoring scheme in primary health care. Journal of Interprofessional Care 2003;17:402-3.

26 Sharpe L, Davies T. Health Service Journal July 2003:30-31.

27 Andrews A, Wallis M. Mentorship in nursing: a literature review. Journal of Advanced Nursing 1999;29:201-7.

28 Joesbury H, Mathers N, Lane P. Supporting GPs whose performance gives cause for concern: the North Trent experience. Family Practice $2001 ; 18: 123-30$.

29 Kersley S. Medical mentoring on the phone. BMJ Career Focus 2006:332:58.

30 Clutterbuck D, interview reported in Snell J. Head to head. Health Service Journal 1999; 109:22-5. 